\title{
LAS ESTACIONES DE ESQUÍ EN LA CORDILLERA CANTÁBRICA
}

\author{
Francisco Feo Parrondo \\ Departamento de Geografía \\ Universidad Autónoma de Madrid
}

\section{RESUMEN}

El esquí ha adquirido en las últimas décadas gran importancia como atractivo turístico en diversas zonas montañosas españolas. Analizamos en este trabajo su evolución reciente en las cinco estaciones y una miniestación de la Cordillera Cantábrica y los proyectos de creación de otras estaciones de próxima apertura.

Palabras clave: Turismo, estación de esquí, Cordillera Cantábrica, impactos ambientales.

\section{ABSTRACT}

In the last few decades skiing has become a very important tourist attraction in several mountainous regions in Spain. Our work analyses the recent development of skiing in five ski resorts and a mini-resort in the Cantabrian Mountain and development projects for other resorts that will be opened soon.

Key words: Tourism, ski resort, Cantabrian Mountain, environmental impacts.

\section{Turismo de invierno: un sector en expansión con alto impacto ambiental}

El turismo de invierno ha adquirido notable importancia en las últimas décadas y «el esquí ha dado lugar en las montañas a los tipos de implantación turística más afines a los litorales» (Valenzuela, 1998-1999: 81). Los primeros ensayos «esporádicos, datan de fines del siglo XIX; ya bastante antes de 1914, el esquí había progresado lo bastante para permitir que se organizasen competiciones civiles y militares. Sin embargo, hacia 1930 fue cuando se impuso ampliamente» (Herzog, 1967: 391). En esta expansión jugó un papel importante, desde 1920, la construcción de teleféricos que facilitan el acceso a zonas de alta montaña y «los intereses de importantes compañías de ferrocarriles que promovieron y financiaron el equipamiento hotelero de las primeras estaciones en los años treinta» (Antón, 2000: 369). En 1967, Herzog señalaba que el esquí «se ha dado a conocer poco a poco y 
luego, en unos cuantos años, ha adquirido un impulso sorprendente, hasta el extremo de que hoy, en las estaciones bien organizadas, hay más gente en invierno que en verano. Es otra auténtica revolución» (Herzog, 1967: 391). Este mismo autor apunta que en los Alpes ya había una «extraordinaria concurrencia a las pistas de esquí. Para Navidad y Año Nuevo, todas las habitaciones quedan reservadas con varios meses de anticipación; otro tanto ocurre en febrero, hacia el carnaval, y por Pascua, en las estaciones donde aún queda nieve por aquellas fechas» (Herzog, 1967: 394).

Tres décadas después, José Fernando Vera constata las grandes diferencias territoriales del turismo vinculado con la nieve: «La distribución de la nieve a escala mundial viene determinada por la localización de los grandes sistemas montañosos y las altas latitudes, si bien su aprovechamiento turístico (estaciones de esquí y montaña) se produce en las zonas próximas a los centros emisores y países con sistemas social, económico y técnico que lo posibilitan. En el mapa del turismo de nieve destacan, principalmente, los Alpes, los Pirineos, los países nórdicos europeos, los sistemas montañosos de América del Norte y los Andes en el hemisferio Sur» (Vera, 1997: 144). Este mismo autor señala que, en Europa, se practica sobre todo en Suiza, Francia, Italia, Austria y Alemania (Vera, 1997: 144-145). Se calcula que más de 50 millones de personas realizan anualmente vacaciones de esquí en Europa (Antón, 2000: 369). En 1995, solamente en los Alpes, existían más de 40.000 pistas con una longitud de $120.000 \mathrm{~km}$, una extensión de 1.000 kilómetros cuadrados, 1200 telesillas con capacidad para transportar a 1'2 millones de personas (Antón, 2000: 370). Mientras, España «cuenta con 28 estaciones de esquí (principalmente en el Pirineo, y también en otros sistemas montañosos), dotadas en su conjunto por 300 remontes mecánicos y que son utilizados cada año por algo menos de 3 millones de esquiadores. Las estaciones de esquí disponen de una oferta hotelera de casi 20.000 plazas, y en sus áreas de influencia la capacidad hotelera se sitúa en 100.000 plazas» (Vera, 1997: 145).

Según Francisco López, en España, «la demanda de zonas esquiables ha sido reciente y su etapa de expansión, al margen de las instalaciones pioneras, se inició en los años sesenta y se consolida en la década siguiente» (López, 1996: 28). En la temporada 1997-1998, las 28 estaciones españolas contaban con 330 remontes mecánicos ( 5 telecabinas, 120 telesillas y 205 telesquís) con capacidad para transportar 298.081 personas/hora, casi 13.000 más que la temporada anterior, lo que permitió el acceso más rápido a los $762 \mathrm{~km}$ esquiables. Había 20.611 plazas de alojamiento en establecimientos en las propias estaciones y otras 89.441 a menos de $35 \mathrm{~km}$ de las distintas estaciones. Estas disponían de 2116 cañones y de 1742 profesores en las escuelas de esquí (López, 1999: 481-482). En la década final del siglo $\mathrm{XX}$, algunas estaciones españolas tienen un incremento espectacular de esquiadores. Es el caso de Sierra Nevada, donde se pasa de unos 490.000 de media anual entre 1984 y 1997 a 918.000 en la temporada 1997-1998, procedentes mayoritariamente de Andalucía, Madrid, Valencia, Alicante, Murcia y con un notable incremento de esquiadores portugueses y de la mitad norte de España (Martínez Salinas, 1998: 119-120). En la temporada 1997-1998, las estaciones aragonesas contaron con millón y medio de esquiadores procedentes de Aragón, Cataluña, País Vasco, Navarra, Madrid, Valencia, Francia, Portugal, Gran Bretaña, Bélgica y Holanda (Callizo et al., 1999: 239-241). El esquí ha dejado de ser un deporte elitista y cada vez cuenta con más adeptos, alcanzando en España una cifra entre 2 y 2'5 millones de esquiadores (El Mundo, 1-12-2005: 12).

En noviembre de 2002, las 29 estaciones españolas de esquí disponían de 331 remontes para acceder a los $837 \mathrm{~km}$ esquiables que se ubicaban entre los $1375 \mathrm{~m}$ de Valgrande-Pajares (la más baja) y los 3300 m de Sierra Nevada (la más alta). También existían grandes diferencias de precios, oscilando entre los 11'50 euros/día de Leitariegos (León) y los 33 de Baqueira-Beret (Lérida) (El País, 9-11-2002, suplemento El Viajero: 1-4). Para la tempo- 
rada 2004-2005 había en España 900 km esquiables divididos entre 853 pistas (139 verdes, 271 azules, 332 rojas y 110 negras), contaban con 341 remontes mecánicos (6 telecabinas, 144 telesillas, 172 telesquís y 21 cintas transportadoras) con una capacidad de 384.858 personas/hora; y 3.687 cañones de innivación con capacidad para 274 km., y unas 19.536 plazas de alojamiento más otras 113.617 situadas en un área de $35 \mathrm{~km}$. (La Nueva España, 12-12-2004: 17). En la temporada 2005-2006, funcionarán 29 estaciones: 5 en la Cordillera Cantábrica, 5 en el Pirineo aragonés, 11 en el Pirineo catalán, 3 en el Sistema Ibérico, 4 en el Sistema Central y 1 en el Sistema Penibético. Para la temporada 2005-2006 hay 888 pistas con $1114 \mathrm{~km}$ de nieve y remontes con capacidad para 400.000 personas/hora y se han invertido más de 73 millones de euros en mejora de remontes, cañones, adecuación de las pistas, etc (El Mundo, 1-12-2005: 12).

Las crisis de las áreas de montaña parece que solo pueden paliarse con turismo de montaña, dentro del cual el que más beneficios económicos ha generado es el esquí alpino ${ }^{1}$. Para Diego Barrado, «el esquí, una de las actividades deportivas de montaña más antiguas, se ha convertido en una amenaza ambiental por la agresión que supone la adecuación del territorio para este uso» (Barrado, 1999: 39). Este mismo autor señala que «los impactos más habituales que provoca pueden encuadrarse en tres aspectos fundamentales. Sobre la biocenosis, provocando la huída de la fauna y la desaparición de la cobertura vegetal, al cortarse para el trazado de las pistas y por la presión del contínuo paso de esquiadores. Sobre el suelo, por el deslizamiento que potencia una erosión ya de por sí alta en lugares de fuerte pendiente y climatología extrema. Finalmente, sobre el paisaje, con la introducción de elementos extraños en lugares altamente visibles, aspecto que alcanza un grado máximo cuando la estación es de permanencia y lleva unido un núcleo urbano» (Barrado, 1999: 281) ${ }^{2}$.

Eduardo Martínez de Pisón ha constatado los profundos cambios de zonas montañosas aragonesas propiciados por el turismo: «la eclosión de construcciones que parecen repentinas, el rápido paso de núcleos ganaderos a colonias de veraneo y esquí, tiene una anterior preparación inevitable en operaciones inmobiliarias que se materializan en el momento administrativo o económico oportuno. Podría ocurrir que sólo elementos dispersos lleguen a recordar los orígenes rurales de ciertos pueblos» (Martínez de Pisón, 2002: 16). Esta afirmación sobre los Pirineos es válida también para otras zonas como Guadarrama, Sierra Nevada y «sin duda ciertas estaciones de esquí donde hay nieve-recurso y accesos rápidos (llego, patino y me voy) - lo que no siempre ocurre - son verdaderas fábricas de ocio masivo en fechas específicas que pueden producir fuertes rentas, ser negocio. Estimuladas por todos los medios disponibles, hasta por el parte meteorológico, son útiles; pero con ello hay que aceptar que en esas fechas puntuales, quiéranlo o no los esquiadores, éstos forman multitudes urbanas concentradas en la montaña (...). Ello depara rentas y diversión de $<$ puente $>$ pero hace $<$ ciudad $>$, inevitablemente, a paisajes que tienen su mayor calidad en ser lo opuesto» (Martínez de Pisón, 2002: 39)3).

1 Las prácticas deportivas en la montaña se han ido diversificando en función del carácter estrictamente deportivo y/o comercial, siendo actualmente muy diversas: alpinismo glacial, alpinismo de dificultad, alpinismo invernal, ascensionismo, escalada deportiva, esquí de travesía, snowboard, senderismo, trekking, etc. (González Fernández et al., 2004: 451).

2 Salvador Antón añade los riesgos por «polución de las aguas por deposición de resíduos líquidos; degradación de las especies vegetales por acumulación de contaminantes atmosféricos provenientes de los vehículos de motor (...), despilfarro de recursos hídricos (...)» (Antón, 2000: 370).

3 Algunas estaciones de esquí, como la aragonesa de Formigal, cuentan con análisis minuciosos sobre su impacto ambiental y paisajístico (Cancer et al., 2001: 299-307). 
El proceso de urbanización turística de carácter residencial asociado al esquí es frecuente también en otros países europeos, especialmente en los Alpes, aunque con notorias diferencias: mientras en Suiza, Alemania y Austria se hace a partir de la expansión de los núcleos rurales preexistentes, en Francia se construyen bloques en altura (Antón, 2000: 370). Ya en 1994, Manuel Castells apuntaba alternativas a las estaciones de esquí en algunas zonas de la Cordillera Cantábrica: «un elemento esencial de la nueva política sobre los Picos de Europa sería la desestacionalización de su visita, concentrada en los meses de verano. Para ello sería necesaria una comercialización del producto nieve, aunque sin recurrir al desarrollo de estaciones de esquí que son demoledoras para la conservación de la naturaleza y atraen un público muy distinto del naturalista, por lo que son incompatibles con el producto naturaleza. En cambio, el esquí de travesía, las excursiones invernales y el ambiente rural de montaña en vacaciones de invierno pueden ser elementos que desestacionalicen» (Castells, 1994: 454).

Para Diego Barrado, «existe una demanda real que será necesario atender, intentando al mismo tiempo causar el mínimo impacto posible y ayudando a la supervivencia de las poblaciones de montaña» (Barrado, 1999: 283) y teniendo en cuenta que «la mayoría de las montañas españolas no son adecuadas, tanto por la altitud como por la latitud, para acoger grandes estaciones» (Barrado, 1999: 282). En el análisis de cada estación haremos mención a los principales impactos medioambientales que genera.

\section{Estaciones de esquí en la Cordillera Cantábrica}

De las 29 estaciones españolas de esquí, cinco se ubican en la Cordillera Cantábrica, contando con un total de 90'95 km esquiables para la temporada 2005-2006: 11'25 en Manzaneda, 5'12 en Leitariegos, 23 en Valgrande-Pajares, 23'8 en San Isidro y 27'78 en Alto Campoo. En este apartado las analizaremos por este orden, de Oeste a Este.

\subsection{Manzaneda (Orense)}

La estación de Manzaneda se ubica a una altura de 1.500 a 1.800 metros en el municipio orensano de A Pobra de Trives, en la ladera nordeste de Cabeza Grande en el macizo de Cabeza de Manzaneda y con accesos desde A Pobra de Trives y Manzaneda por carretera, distando $45 \mathrm{~km}$ de la estación ferroviaria de A Rúa (Orense) y 200 del aeropuerto de Labacolla (Santiago de Compostela). Está a $90 \mathrm{~km}$ de Orense, 110 de Ponferrada, 115 de Lugo, 190 de Pontevedra, 195 de Vigo, 210 de La Coruña y 225 de El Ferrol.

En 1991, Tomás Vega señalaba que la estación contaba con las instalaciones necesarias para practicar deportes de nieve (Vega, 1991: 35). En 1998, tenía 13 pistas con una longitud de 7'5 km a las que se accedía a través de 6 telesquís y 1 telesilla siendo su capacidad máxima de 4.320 esquiadores/hora (Simó et al, 1998: 136-137). Desde el 2002 cuenta con 16 pistas con un total de 10'5 km esquiables a las que se accede por 4 telesquís y 2 telesillas con capacidad para transportar a más de 5.700 viajeros/hora (La Voz de Galicia, 15-122002: 3). Dispone de 3 cañones de nieve artificial. Se practica el esquí en sus modalidades alpino y de fondo por expertos y principiantes.

La estación cuenta con equipamientos diversos: apartamentos, albergue, bungalows, enfermería, restaurante, cafeterías, comercios, discoteca, oficina de información, escuela de esquí, alquiler de material deportivo, piscina cubierta y climatizada, saunas, lavandería, aparcamiento, pistas de tenis, campo rústico de golf, etc. En las proximidades existen hostales en Manzaneda y Villariño de Conso, casas de turismo rural en Drados, supermercados, campings, etc. Ya en 1998, se había «creado una infraestructura de apartamentos y hoteles 
que contrastan fuertemente con la pobreza del entorno» (Torres et al., 1998: 172). Cuenta con casi mil plazas de alojamiento a menos de $35 \mathrm{~km}$ de la estación.

$\mathrm{Al}$ estar rodeada de 2.000 hectáreas de bosque y tener cerca, al sur, el parque natural do Invernadeiro con 5.722 hectáreas en las que predomina el rebollo (quercus pyrenaica), los visitantes practican en su entorno el montañismo, espeleología, senderismo, ciclismo de montaña, excursiones a caballo, equitación en picadero, etc., complementando y diversificando las actividades de ocio de la estación. Este proceso está en expansión con nuevas oportunidades: tiro con arco, campo de futbol, canchas de baloncesto y voleibol, pistas de karts para derrapar, clases de esquí con monitores federados, aula de naturaleza para jóvenes de 8 a 18 años en la sierra de Queixa, juegos tradicionales (petanca, bolos, malla), iniciación a primeros auxilios en alta montaña, manejo de brújula.... Asimismo, se tiende a potenciar el turismo cultural visitando puentes romanos del entorno, el monasterio de Sobrado, la fortaleza medieval de Manzaneda, iglesias barrocas, restos de minas romanas, etc.

Con esta diversificación de actividades se trata de traer turistas durante todo el año por las limitaciones de la estación de esquí: la nieve permanece poco tiempo y «el tipo de turista que accede a estas instalaciones es fundamentalmente regional y de una clase media-alta, debido a los elevados costes que comporta» (Torres et al., 1998: 172). En la campaña 2004-2005 (del 26 de noviembre al 3 de abril), los precios para un día de forfaits ascendían a 20 euros para adultos y 13 para niños de menos de doce años, los pases anuales costaban 210 euros para adultos, 150 para menores de doce años, 105 para mayores de 65 años y 20 euros para menores de cinco años y la subida y bajada en telesilla suponía 5 euros por persona reduciéndose a 4 para grupos organizados de un mínimo de veinte personas (www.manzaneda.com).

\subsection{Leitariegos (León)}

La estación está situada entre 1485 y 1700 metros de altitud en el término leonés de Villablino, en el límite con el asturiano de Cangas del Narcea. En 1992 contaba con un telesilla, un telesquí y dos telebabis, escuela de esquí, alquiler de material, dos cafeterías y un restaurante a pié de pista y 231 plazas hoteleras en un radio de $15 \mathrm{~km}$. Se abrió una guardería blanca para acoger a niños de tres a seis años y se dan cursos a cargo de 13 profesores de la escuela de esquí dirigidos a interesados de todas las edades (La Maniega, 66, 1992: 11).

Pese a las visitas de miles de personas del suroeste asturiano y noroeste leonés en invierno y, sobre todo, en primavera, la «estación invernal adolece de las infraestructuras necesarias para convertirse en un centro turístico-deportivo invernal» (La Maniega, 69, 1992: 21). La prensa asturiana y leonesa, a lo largo de la década de los noventa, insistió frecuentemente en la necesidad de que las dos diputaciones y los ayuntamientos de Villablino y Cangas del Narcea realizasen inversiones para diversificar la economía y generar empleo en un momento que la minería de la zona atravesaba por una profunda crisis. En 1998, se acordó invertir 300 millones de pesetas en mejorar los remontes (3 telesquís y 1 telesilla) y remodelar el viejo parador (La Maniega, 107, 1998: 19).

En 1998 contaba con 7 pistas (de las que 3 eran para iniciación) y sólo 3’69km a las que podían acceder 2.700 esquiadores/hora en los 3 telesquís y 1 telesilla, La estación disponía de hotel y albergue, aparcamiento, oficina de información, alquiler de material, cafetería, restaurante, autoservicio y escuela de esquí (Simó et al., 1998: 138). Las localidades próximas de Villablino y Cangas del Narcea contaban con hoteles, hostales, tiendas, restaurantes, farmacias, servicios médicos, etc. (Simó et al, 1998: 141). Estas autoras constatan el ambiente familiar y tranquilo de la estación propiciado por la no masificación 
de visitantes y por el entorno natural. Asimismo, el abandono ganadero hace que aumente la superficie arbolada y de matorral y la fauna (jabalíes, corzos, gamos, urogallos, osos...) (Simó et al., 1998: 138-139).

Las obras de ampliación iniciadas por la Diputación de León se paralizaron en 1997 por invadir un monte de utilidad pública en territorio asturiano que se incluía en la Reserva Natural Parcial del Cueto de Arbás en la que se conservan osos pardos. Aunque la estación está mayoritariamente en el municipio de Villablino, una pista y un telesquí están en terrenos de Cangas del Narcea y otro a caballo entre ambas comunidades. Se preveía construir dos nuevas pistas, una en cada provincia, que tienen problemas por el impacto ambiental (La Maniega, 114, 2000: 6), fraccionando la población de osos de la zona. La Consejería de Medio Ambiente de Castilla-León, en su evaluación de impacto ambiental señalaba que las pistas deberían estar por debajo de los 1.800 metros de altitud y el Principado bajaba la cifra a 1.600 m., lo que difícilmente permitirá contar con garantías de nieve a lo largo de toda la temporada (La Maniega, 116, 2000: 8).

A las disputas entre empresarios y ecologistas (La Maniega, 117, 2000: 5) se unió el debate sobre el deslinde entre Cangas del Narcea y Villablino al discrepar el Principado con el Instituto Geográfico Nacional que incluía la estación en territorio leonés (Diario de León, 19-5-2001: 22) ${ }^{4}$. Este situación hizo que no mejorasen las instalaciones y que Leitariegos fuese, con Valgrande-Pajares, la única estación de la Cordillera Cantábrica que no disponía de cañones de nieve artificial (La Nueva España, 3-3-2001: 18). Isidoro Rodríguez y Adelino Campos califican a Leitariegos como una «modesta estación de esquí con unas pequeñas instalaciones, que suele ser visitada con asiduidad durante el invierno por los habitantes de la zona» (Rodríguez Cubillas et al, 2003:165), pese a lo cual contó con 11.200 esquiadores en la temporada 2002-2003 (Diario de León, 13-11-2003: 11).

En diciembre de 2003 se inaugura un albergue con 26 plazas, cafetería y restaurante financiado por la Consejería de Educación, Cultura y Turismo de Castilla-León y la Diputación de León (Diario de León, 13-11-2003: 11) mientras las instalaciones de esquí contaban con 2'75 km. esquiables repartidos entre 4 pistas a las que se accedía por dos remontes (La Nueva España, 26-12-2003: 54). En primavera del 2004 se inician obras encaminadas a instalar nuevos remontes que practicamente cuadruplicarían el número de esquiadores transportables pasando de 1.320 a 4.440, a ampliar en 5'5 km los esquiables, asistencia toda la temporada de Cruz Roja, instalar cañones en una segunda fase...(Diario de León, 13-11-2003: 11). Fruto de esta ampliación, en la temporada 2004-2005 contó con 6’5 km. esquiables repartidos entre 8 pistas, 3 telesillas y 2 telesquís tras invertir 2'5 millones de euros. Se han duplicado las instalaciones gracias a que 16' 5 hectáreas pasaron de Asturias a León permitiendo crear nuevas pistas y el telesilla de La Gobia. También se construyeron numerosas barreras para evitar la fuga de nieve con el viento, uno de los mayores problemas a los que estaba sometida la estación.

En 2005 estaba previsto construir tres nuevos remontes, una cafetería a 1.700 metros, instalar cañones para mantener un nivel de nieve adecuado durante toda la temporada, nuevas máquinas pisapistas, un camión quitanieves, motos de nieve, sistema de megafonía, máquinas expendedoras automáticas de billetes, etc., lo que supondría una inversión de 6'5 millones de euros (La Nueva España, 8-12-2004: 19). El excelente entorno de la estación (está en plena Reserva de la Biosfera del Valle de Laciana y rodeada por el Parque Natural de Somiedo y por la Reserva de la Biosfera del Parque Natural de Fuentes del Narcea,

4 Los conflictos sobre deslindes se remontan a 1928 cuando el Instituto Geográfico y Catastral realiza el primero, ratificado en 1946. Resurge en 1997 al negarse el Principado a cambios que le suponían perder terreno. 
Ibias y Degaña en el que se ha incluído la Reserva de Muniellos) es un atractivo para los visitantes pero supone limitaciones a su posible expansión: el Plan Rector de Uso y Gestión (PRUG) del Parque Natural de Fuentes del Narcea, Ibias y Degaña impide ampliar la estación de esquí de Leitariegos, al menos en territorio asturiano, y también practicar otros deportes, que circulen vehículos, crear nuevas carreteras, explotar minas a cielo abierto, etc. (El Comercio, 7-3-2005: 24). Estas medidas han sido recurridas por todos los partidos políticos de Cangas del Narcea que reclaman poder construir nuevas carreteras, autovías, líneas férreas de largo recorrido y la instalación de complejos deportivos, de ocio, culturales o turísticos entre los que se incluye la ampliación de la estación de esquí, de sus remontes mecánicos y teleféricos (La Nueva España, 16-10-2005: 18).

Actualmente existe un elevado número de alojamientos y hostelería en las localidades de Villablino, Caboalles, Vallao, Las Mestas, Cangas del Narcea ${ }^{5}$, Villacibrán y Villaseca que permiten atender la demanda de los esquiadores durante los 149 días, 70 de temporada alta (domingos y festivos) y 79 de baja (el resto) del 27 de noviembre de 2004 a 24 de abril de 2005. La oferta de alojamientos se incrementará notablemente con la reconversión del antiguo monasterio de Corias en Parador Nacional que contará con 90 habitaciones para 180 personas (La Maniega, 147, 2005: 12-13).

Los precios de los días de temporada alta casi duplican a los de temporada baja: 12 ' 50 y 7'50 euros/día respectivamente para adultos, 8'50 y 6 euros para infantil y 10'50 y 6 euros para agencias; 131 euros para abonos anuales de adultos, 92 para infantiles, 65 para veteranos y 71'40 para familias numerosas (www.leitariegos.com). Con estos precios, «sigue siendo la estación más barata de España» (El País, 19-11-2005, suplemento El Viajero: 7), alcanzando más de 30.000 esquiadores en la temporada 2004-2005 (La Nueva España, 24-4-2005: 14). La situación mejorará con la instalación de 68 cañones de nieve artificial para la que se han presupuestado casi tres millones de euros (La Nueva España, 12-1-2006: 18).

Se pueden alquilar equipos completos, esquís, botas, bastones, equipo de snow, botas y tablas de snow, etc., y la escuela de esquí de Leitariegos desarrolla durante todo el año actividades muy diversas: clases de esquí, telemark, snowboard, tenis, espeleología, tiros con arco, BTT, piragüismo, señalización de rutas, clases para jubilados, bici-esquí, etc. (www.leitariegos.com).

Parte de los visitantes asturianos proceden del occidente del Principado, zona muy afectada por el envejecimiento y éxodo rural y por la crisis del sector minero que había impulsado un crecimiento rápido de Tineo y Cangas del Narcea en décadas anteriores. Ambos problemas económicos se acentúan porque el suroccidente astur «es un área que ha contado, y todavía cuenta, con el lastre de su deficiente red de comunicaciones y su escasa accesibilidad dentro del sistema territorial asturiano» (Rodríguez y Menéndez, 2005: 44). Una situación similar se da en la zona leonesa próxima a Leitariegos y se paliaría parcialmente si se construye la autovía La Espina-Ponferrada, anunciada por el Gobierno en el verano del 2005, para la que ya hay propuestos varios itinerarios alternativos.

\subsection{Valgrande-Pajares (Asturias)}

A una altitud entre 1375 y 1890 metros, es una de las primeras estaciones de esquí españolas al beneficiarse de comunicaciones preexistentes como la carretera Gijón-León (desde 1833) y el ferrocarril inaugurado en 1884 (González Crespo et al., 2003: 85 y

5 En el 2001, Cangas del Narcea tenía 21 establecimientos hoteleros con un total de 288 plazas (Rodríguez y Menéndez, 2005: 219). 
123). Dista 60 km de Oviedo y León, 90 de Gijón, 185 de Zamora, 190 de Valladolid y Palencia, 250 de Burgos, 290 de Lugo, 330 de Orense, 370 de Santiago, 390 de Madrid y La Coruña y 430 de Pontevedra (www.valgrande-pajares.com). En 1898, Juan Menéndez ya apuntaba que en los pueblos del entorno de Pajares la nieve llegaba a 1'5 metros de espesor en los inviernos duros y si hacía viento, los habitantes tenían que «hacer minas para salir de las casas y comunicarse con las de sus vecinos» (Menéndez Pidal, 1898 :288). Las precipitaciones invernales en forma de nieve son muy irregulares: de 2 a 34'3 días por año (Sendin, 1997: 169).

Manuel Sendin constata que el entorno de Pajares es área de recreo desde los años veinte para burgueses ovetenses y gijoneses que imitan a homólogos madrileños y catalanes creando los primeros clubes de montaña y excursionismo: «estudiantes burgueses de Oviedo y Gijón inician la práctica del esquí en las nevadas pendientes de Pajares. La línea férrea a Castilla actúa como vía de penetración de este frente pionero. El éxito de la naciente estación se ve acompañado de la construcción de un hotel, en 1924» (Sendin, 1997: 176). Tras la guerra civil, el despegue económico, la motorización y el incremento de esquiadores forzó a la ampliación y mejora de las instalaciones de Valgrande-Pajares ${ }^{6}$.

En 1952, los esquiadores que llegaban en tren tenían que subir $5 \mathrm{~km}$ a pié hasta el alto del puerto, situación que se palía en 1953 con el telesquí de la Cerra, uno de los primeros junto con La Molina y Candanchú en los Pirineos, que contribuyó al despegue de la estación, ampliada en 1969 y que mejoró con la construcción del albergue Peña Ubiña (19691970), nuevos remontes y ampliación de la superficie esquiable en los setenta. En 1984 se inauguraron otro telesilla y un telesquí (La Voz de Asturias, 2-2-2004: 30), no haciéndose casi nuevas obras hasta finales de los noventa (El Comercio, 5-3-2004: 68). Sin embargo, junto con el trazado de la autopista del Huerna y la presencia de cables de alta tensión, la estación contribuyó a que los frondosos hayedos de la cabecera del río Valgrande se redujeran de unas 3000 ha en 1970 a 1000 en 1997 (Sendin, 1997: 169).

En 1998 contaba con $21 \mathrm{~km}$ esquiables repartidos entre 35 pistas a las que se accedía con 13 remontes (10 telesquís y 3 telesillas) con una capacidad de 8.480 esquiadores/hora. Se podía practicar esquí nocturno, snowboard y monoesquí. Contaba con un área de servicios en Brañillín, a pié de pista, con aparcamientos, alojamientos, oficinas, cafetería, escuela de esquí, clínica y alquiler de material. En el entorno hay hotel en Puerto de Pajares, restaurantes en Busdongo, Arbás y Pajares y servicios sanitarios en Villamanín (Simó et al, 1998: 142-145). En el entorno existen también hostales, casas rurales, alquiler de apartamentos, campings, posibilidad de practicar golf, senderismo, escalada, tiro con arco, descenso de barrancos, paseos en bicicleta y a caballo, gran variedad de flora y fauna (incluyendo osos pardos y urogallos) y monumentos prerrománicos (Santa Cristina de Lena), la colegiata de Arbás, etc. En verano, desde mediados de los cincuenta, se practica el esquí sobre hierba (La Nueva España, 30-8-1999, suplemento Verano: 4).

La irregularidad en la existencia de nieve se traduce en un número irregular de visitantes, situación que se palía con las constantes competiciones para mujeres y hombres en categorías senior, cadete, juvenil, benjamines, etc., y con la puesta en marcha de la Semana Blanca por el Principado para aumentar el número de escolares visitantes ${ }^{7}$.

6 La evolución histórica de la estación ha sido analizada minuciosamente por Martínez Fernández (2003: 215-226).

$7 \quad$ Las competiciones se practican por mujeres y hombres en Pajares desde finales de la guerra civil y desde entonces acuden escolares a realizar prácticas deportivas y de educación física, separados por sexo hasta 1977 (Carbajosa, 1999: 19 y 217-218). 
A lo largo de 2001 se crea una pista de 1'2 km con nieve artificial en La Hoya, se colocan paravientos nuevos para garantizar nieve en sitios con fuerte viento. La pérdida de esquiadores, en beneficio de San Isidro, incita a renovaciones urgentes: cañones de nieve artificial, sustitución de telesquís por telesillas y ampliación de la superficie esquiable para recuperar los usuarios de los años setenta y ochenta (La Nueva España, 21-3-2001 :16). El Ayuntamiento de Lena autoriza las obras que se financian parcialmente con los fondos mineros y, el 25 de enero de 2002, se inauguran 21 cañones que permiten aumentar la superficie con nieve y el número de esquiadores. Dichos cañones supusieron una inversión de 1'5 millones de euros (Diario de León, 3-1-2002:19) pero fueron poco rentables por las temperaturas superiores a las habituales (La Nueva España, 31-3-2002: 13).

En verano de 2002 se inician obras para mejorar las instalaciones: ampliar el parking de 600 a 800 vehículos, nuevas construcciones residenciales, ampliación en 2 km del sistema de nieve artificial, un telesilla, reforma del albergue Toribión, etc. (El Comercio, 29-62002: 31). A los cañones existentes se añaden otros 29 lo que se traduce en un aumento del suministro eléctrico de 700 a 2750 kilovatios (La Voz de Asturias, 8-11-2002: 24) aunque no impidieron que la estación estuviese cerrada tres semanas por falta de nieve (La Nueva España, 10-1-2003: 5), compensándose con casi treinta competiciones oficiales organizadas por la Federación de Deportes de Invierno del Principado de Asturias (FDIPA) y con unos 1700 niños que acudieron a la Semana Blanca.

La nieve artificial palió la escasez de otras pistas en diciembre de 2003, acudiendo unos 7200 esquiadores en el puente de la Constitución que utilizaron 32 pistas y 10 remontes, pese a lo que fue una mala temporada con cierres intermitentes por la escasa superficie esquiable pese a la instalación de varios kilómetros de paravientos, claves para mantener la nieve. La situación se palió una vez más con los 2000 escolares y con las nieves de marzo de 2004 que permitieron llegar el día siete a 11.500 esquiadores, cifra récord desde hacía ocho años (La Voz de Asturias, 8-3-2004: 22). A diferencia de otras estaciones, los cañones no impidieron grandes diferencias en el número de esquiadores (mínimo de 2483 en diciembre de 2003 y máximo de 30075 en marzo de 2004) ni de otros visitantes (14525 en febrero y 79059 en marzo de 2004, mínimo y máximo respectivamente (La Voz de Asturias, 4-5-2004: 29) pese al incremento con respecto a temporadas anteriores: 22533 esquiadores en 2001-2002, 47817 en 2002-2003 y 48665 en 2003-2004, por el aumento de los procedentes de Galicia y norte de Portugal.

La temporada 2004-2005 partió con la adquisición de una máquina pisanieves de última generación, ampliación de la pista del Tubo, reforma de las instalaciones de servicios, nuevo telesilla con capacidad para transportar 1500 viajeros/hora triplicando la capacidad del antiguo telesquí al que sustituyó, varios kilómetros más de paravientos, etc., coincidiendo con el 50 aniversario de la estación. Las campañas publicitarias en Oporto y Lisboa han contribuído a incrementar las visitas de esquiadores del centro y norte de Portugal (los del sur van a Sierra Nevada) al disponer de una única estación de esquí (Serra da Estrella en el NE) con poco más de 6 km esquiables. En la temporada 2004-2005, contó Valgrande con 8 telesquís y 5 telesillas, $23 \mathrm{~km}$ de pistas y 3 de nieve artificial, escuela de esquí y los servicios básicos para la práctica de esquí alpino, nocturno, de fondo, de travesía, snowboard, snowblade, gimnasio, alquiler de equipos, servicio de reparación de esquís, jardín de nieve, etc. (www.valgrande-pajares.com), lo que posibilitó que algunos fines de semana disfrutasen de las instalaciones unos 80.000 usuarios (La Nueva España, 13-3-2005: 1516), llegando a una ocupación total de las plazas hoteleras en Semana Santa (La Voz de Asturias, 18-3-2005: 25) y a unos 2000 niños de casi 70 colegios en la Semana Blanca escolar (La Voz de Asturias, 8-4-2005: 31). En total, se recibieron 91.672 esquiadores (con un incremento de casi el 70\%) y 544.339 visitantes, las cifras más altas desde su apertura 
hace medio siglo, generando un total de 130 empleos directos en los distintos servicios (La Voz de Asturias, 29-4-2005: 70).

Para la temporada 2005-2006 se ha ampliado la pista El Tubo, se han instalado nuevos cañones, reformado la cafetería Telesilla, etc., estando el Principado estudiando la posibilidad de crear más plazas hoteleras en el entorno y reabrir el parador de Pajares ante el constante incremento de esquiadores que acuden a Valgrande tras la crisis de los años noventa (La Voz de Asturias, 10-12-2005: 22). Las previsiones de crecimiento turístico ligado al esquí también aparecen en el PGOU de Lena, que reserva unos 10.000 metros cuadrados para instalaciones hoteleras (El Comercio, 10-12-2005: 12).

\subsection{San Isidro (León)}

La estación invernal de San Isidro está situada en el límite norte del municipio leonés de Puebla de Lillo, lindando con Asturias. Ocupa unas 2.000 hectáreas y es propiedad de la Diputación Provincial de León desde que en 1969 compró los terrenos a la familia Asís Garrote (Martínez Carrión, 2002: 45), iniciando las obras de la estación que es inaugurada el 26 de mayo de 1974 contando con tres telesquís y un telesilla. Se invirtieron por la Diputación Provincial de León, Delegación Nacional de Educación Física y Deportes y por el Ministerio de Información y Turismo unos 70 millones de pesetas de los que 7' 5 se destinaron a adquirir terrenos, más de 41 a instalaciones deportivas y elementos de remonte y más de otros 20 a obras de urbanización. En los años siguientes se mejoraron los accesos por carretera desde León y en el Plan Operativo Local (POL) de la Diputación Provincial (1994) se incluyó la señalización de la estación invernal de San Isidro en las entradas provinciales por carretera (Rodríguez Lago, 1995: 23 y 26). Esto no ha impedido que, en fechas concretas, se generen considerables atascos de circulación.

Ubicada entre 1500 y 2100 metros, dista 66 km de Oviedo, 83 de León, 202 de Valladolid, 350 de La Coruña, 415 de Madrid, 402 de Oporto y 706 de Lisboa, ubicándose los aeropuertos de Oviedo y León a 80 y 90 km y las estaciones de FEVE de Boñar y Collanzo distan 35 y $20 \mathrm{~km}$ (www.estacionsanisidro.com y www.dipuleon.com/sanisidro). Estas distancias son ligeramente inferiores a las apuntadas en publicaciones de hace unos años (Simó et al., 1998: 146, y Martínez Carrión, 2002: 48-49) por la mejora de las carreteras de acceso desde León y Asturias.

Cuenta con 23 pistas (2 verdes, 8 azules, 11 rojas y 2 negras) con 23'821 km esquiables repartidos entre cuatro zonas (Salencias, Cebolledo, Resquejines y Riopinos), a los que pueden acceder 11.960 esquiadores/hora entre los 12 remontes ( 8 telesquís y 4 telesillas) que comunican entre sí las tres zonas altas mientras Salencias y Cebolledo lo hacen por autobuses gratuitos en temporada alta y festivos. Cuenta, asimismo, con dos itinerarios de esquí fuera de las pistas (Simó et al, 1998: 149).

Sus 53 cañones de nieve artificial de alta presión garantizan nieve en una pista de casi dos kilómetros y la práctica de esquí desde noviembre hasta finales de abril (Martínez Carrión, 2002: 46-47). Se inauguraron en 1998 y han contribuido a dinamizar la estación con la presencia de numerosos esquiadores del norte de España y Portugal (La Nueva España, 1-12-2001: 14). En Semana Santa del 2001 mantuvo las pistas abiertas gracias a los cañones mientras Pajares estuvo cerrado (La Nueva España, 15-4-2001: 15). El 1 de diciembre de 2001 inauguró la temporada 2001-2002 con unos 5.000 visitantes que esquiaron en 20 de los 24 km esquiables gracias a la producción de nieve artificial por los 53 cañones existentes (La Nueva España, 2-12-2001: 17), contradiciendo lo apuntado hace más de dos décadas por José Ramón Lueje, quien calificaba las laderas del puerto de San Isidro como sumamente apacibles pero que «conservan muchos meses la nieve» (Lueje, 1984: 58). 
La estación dispone de una gama de servicios diversos: escuela de esquí, alquiler de material, restaurantes, aparcamientos, hotel, ambulancia, Cruz Roja, médico, oficina de información, máquinas pisapistas, moto de nieve, etc. Es amplia la oferta de alojamientos (hoteles, hostales, casas rurales, chalets, apartamentos, pensiones, campings) tanto en localidades de la vertiente leonesa como en la asturiana. Como ha apuntado Francisco Martínez, la «creciente inversión en hoteles, restaurantes, bares, cafeterías, comercios, casas rurales, campings, etc., modifica el modo de vida del municipio y contribuyen a fijar población» (Martínez Carrión, 2002: 15), acelerándose el proceso desde la aprobación de la futura estación de Fuentes de Invierno en la ladera norte del puerto de San Isidro.

En la temporada 2002-2003 se construye un edificio de servicios múltiples y un aparcamiento para abrir la estación al público por Riopinos desde el sur (La Voz de Asturias, 8-11-2002: 61). Se estrena también cafetería en Riopinos que incluye asimismo servicio de alquiler de esquís y taquillas para los remontes (La Nueva España, 6-12-2002: 15) con una inversión de 270455 euros a cargo de la Diputación Provincial de León y de la Junta de Castilla-León (La Nueva España, 10-1-2003: 5).

A finales de noviembre de 2003, la estación contaba con 67 trabajadores para atender a los visitantes. Se ponen en marcha casi mil nuevas plazas de aparcamiento: para 600 coches y 60 autobuses en Salencias a ambos lados de la carretera de Asturias a León y se amplía el parking existente en Cebolledo con 200 plazas. Se instalan seis nuevos cañones en Cebolledo y el alquiler de esquís se traslada de Salencias al edificio Pico Agujas (Diario de León, 28-11-2003: 9). Se llega a un acuerdo con la Diputación leonesa para organizar en San Isidro cursillos gratuitos para la preparación de monitores de esquí para la futura estación de San Glorio (Diario de León, 11-11-2003: 10).

A fines de 2003, en un radio de 50 km existían 1533 plazas hosteleras y otras mil en el camping de Boñar, dependiendo bastante las primeras de las visitas de esquiadores. Se prevé crear cerca de 500 nuevas plazas hoteleras desde primavera de 2004 (Diario de León, 4-12-2003: 8). La Diputación leonesa pretende que los proyectos de mejora y ampliación de las instalaciones invernales de San Isidro las realicen y financien las constructoras del área residencial de Salencias en las inmediaciones de la estación de esquí: tanto las nuevas pistas de Requejines y Riopinos como la construcción de un polideportivo y una piscina cubierta. La constructora lo será de siete hoteles, 200 apartamentos y un centro comercial, pretendiendo que la estación sea una referencia incuestionable al ampliarse servicios, alojamientos y $8 \mathrm{~km}$ más de superficie esquiable (La Nueva España, 11-1-2004: 16).

La Diputación de León impulsará la estación de esquí con varias instalaciones deportivas (entre ellas un campo de golf) y otros equipamientos (centro comercial y 350 chalets y apartamentos) en los que invertirá 3'6 millones de euros que potenciarán San Isidro y convertirán a Fuentes de Invierno cuando se inaugure en un mero complemento de la estación de la vertiente leonesa (La Voz de Asturias, 27-4-2004: 22).

La expansión urbanística para construir 7 hoteles, 93 chalets adosados, 149 apartamentos, 40 bungalóst, 27 viviendas unifamiliares, campo de golf, centro comercial y balneario es adjudicada a la empresa Esquí Golf Resot, con sede social en Meres (Siero) y participada por capital leonés, asturiano y de los Fernández Ochoa, con un presupuesto de 57 millones de euros (La Nueva España, 13-2-2005: 35), calificándola algunos como la «Marbella blanca» (La Nueva España, 6-2-2005: 18). En mayo de 2005 se inician las obras de construcción de una piscina climatizada, gimnasio, campo de golf de nueve hoyos, polideportivo cubierto, etc., para romper la estacionalidad generada por el esquí (Diario de León, 10-1-2005: 10). Los hoteles y bungalóst se construirán a partir de 2006 y se ampliarán pistas e instalarán nuevos remontes y cañones desde 2007, generando unos 400 puestos de trabajo durante 
los cuatro años que duren las obras previstas y 200 estables una vez finalizadas (Diario de León, 8-5-2005: 14).

Los equipamientos (alojamientos y hostelería) son muy numerosos y variados en las localidades próximas de la vertiente leonesa: en la propia estación, Isoba, Puebla de Lillo, Cofiñal, Redipollos, Valdecastillo, Boñar, Renedo de Curueño, Lario, Liegos, Sobrepeña, La Vecilla, Mata del Curueño, Matallana de Torío y Prioro. También se han diversificado notablemente en la vertiente asturiana: Felechosa, Collanzo, Serrapio, Corigos y Moreda (www.estacionsanisidro.com).

Pedro V. Sánchez, alcalde de Puebla de Lillo, en la introducción del libro de Francisco Martínez, no duda en señalar que «la estación de esquí de San Isidro se ha convertido en el centro deportivo de invierno más importante de todo el noroeste español» (Martínez Carrión, 2002: 7). Este autor constata que Puebla de Lillo es un «municipio de referencia obligada en el sector del deporte de la nieve tanto a nivel provincial, como en la Comunidad de Castilla y León y, cada vez más, a nivel internacional, ya que los aficionados portugueses se han convertido en uno de los colectivos que acuden con mayor frecuencia y número a las pistas de esquí en la vertiente leonesa-astur» (Martínez Carrión, 2002: 12).

San Isidro atrae todos los años a «miles de aficionados a la nieve procedentes de todo el norte de España y de Portugal» (Martínez Carrión, 2002: 45). En la campaña 1999-2000 se contó con unos 250.000 visitantes, mayoritariamente de Castilla-León, Asturias, Galicia y País Vasco (Diario de León, 19-3-2002: 1 y 21). En la temporada 2000-2001 acudieron 170.000 esquiadores frente a los 37.000 de Pajares (La Nueva España, 13-11-2001: 15). En la temporada 2001-2002 accedieron más de 300.000 esquiadores y otros 40.000 visitantes (La Voz de Asturias, 8-11-2002: 61), siendo una gran temporada gracias a la nieve artificial que facilitó que algún fin de semana llegasen hasta 20.000 visitantes con los consiguientes atascos en las carreteras procedentes de León y Asturias (La Nueva España, 21-1-2001: 62). Un $60 \%$ de los usuarios de los más de 3000 bonos anuales vendidos fueron asturianos por la baja actividad de Valgrande-Pajares que aún no había podido poner en marcha sus nuevos cañones de nieve artificial (La Nueva España, 31-1-2002: 11).

En la temporada 2002-2003, la falta de nieve retrasó la apertura de la estación y redujo el número de esquiadores a 240.000 visitantes, 30.000 menos que la temporada anterior, con unos 2.015 usuarios diarios de los remontes. En el descenso pudo influir también el incremento de un $4 \%$ de los precios, oscilando para adultos entre 14 y 19 euros (temporadas baja y alta), para infantiles de 10'50 a 16'50 y costando 4'50 euros los remontes (Diario de León, 28-11-2003: 9). Las lluvias que redujeron el espesor de la nieve y los vientos de hasta $130 \mathrm{~km} /$ hora hicieron que algunos días hubiera menos visitantes aunque se llegó a unos 3000 abonos vendidos (La Voz de Asturias, 11-12-2002: 14). En el puente de la Constitución hubo unos 7.000 visitantes por falta de nieve (La Voz de Asturias, 10-12-2003: 35) y en Navidades el viento obligó a cerrar pistas y la nieve a circular con cadenas lo que convirtió la temporada 2003-2004 en regular, mejorando gracias a las «semanas blancas escolares» de enero, febrero y marzo de 2004 (La Voz de Asturias, 20-1-2004: 32), al incremento del grosor de nieve a comienzos de marzo que contribuyó a cerrar la temporada con 255.384 esquiadores, de los que un $60 \%$ procedían de Asturias, un $26 \%$ eran leoneses y el resto de Galicia y Portugal (La Nueva España, 2-5-2004: 14).

Para la temporada 2004-2005 (del 27 de noviembre a 24 de abril) contó con 23 pistas (2 verdes, 8 azules, 11 rojas y 2 negras) a las que se accedía con doce remontes (4 telesillas y 8 telesquís), repartiéndose entre 70 días de temporada alta y 79 de baja, división que supone notables oscilaciones en el precio pagado por los esquiadores: 19'50 y 14'50 euros/día para adultos, 17 y 11'50 para infantiles, etc. (www.estacionsanisidro.com). Estas diferencias no influyen para que el mayor número de visitantes se concentre en puentes como el de la 
Constitución con unos 6.000 visitantes que llenaron al completo hoteles y apartamentos (La Nueva España, 7-12-2004: 12) y en Navidad con casi 43.000 esquiadores pese al cierre de tres días por el temporal de nieve. Entre todo diciembre y nueve primeros días de enero del 2005 hubo 86.000 esquiadores y otros 12.000 visitantes (Diario de León, 10-1-2005: 10). En realidad estuvo 128 días abierta y se recaudaron 2'84 millones de euros gracias a que se superó el número de visitantes de la temporada anterior (La Voz de Asturias, 29-4-2005: 70), tendiendo a diversificarse su lugar de procedencia.

En el importante número de turistas juega un papel significativo la casi constante mejora de instalaciones y equipamientos. Para la temporada 2004-2005 se remodeló la pista Las Liebres con disminución de pendientes y ensanche, se inauguró un edificio de servicios múltiples en Cebolledo, nueva urbanización en Salencias, nueva red de abastecimiento de agua y nuevo alumbrado público en urbanización Las Piedras, remodelación de hostales, etc. (La Voz de Asturias, 29-1-2005: 75).

A lo largo de la temporada se organizan diversas competiciones de esquí alpino para adultos e infantiles, campeonatos regionales, etc. (www.estacionsanisidro.com). Asimismo, es muy amplia la oferta de cursos de la escuela de esquí que cuenta con un elevado número de profesores que imparten cursos de todos los niveles desde iniciación a competición en las modalidades de esquí, snowboard y telemark con precios que oscilaron en la temporada 2004-2005 de 60 a 84 euros por quince horas (mañanas) y de 36 a 50'40 euros por doce horas (tardes) (www.estacionsanisidro.com).

Además del esquí, la comarca del Alto Porma ofrece a los visitantes una gran variedad de atractivos turísticos a lo largo de todo el año: calzada y puentes romanos en Boñar y Valdepiélago, cuevas de Valporquero, iglesia prerrománica en Cofiñal, torreones medievales en Puebla de Lillo y La Vecilla, caza, pesca de truchas en el Porma, recolección de setas, senderismo, montañismo, deportes nauticos (vela y windsurf) en el pantano del Porma, rutas a caballo, parapente, rica gastronomía (embutidos, nicanores de Boñar, quesos artesanales, orujo leonés, etc.) y una gran riqueza paisajística con bosques autóctonos en la Reserva Nacional de Caza de Mampodre que, a su vez, está dentro del Parque Regional de Picos de Europa por lo que tanto la flora como la fauna gozan de protección oficial, salvo en la estación de esquí, lo que sirve de revulsivo para el turista que puede contemplar bosques autóctonos, de hayedos y robledales con rebecos, corzos, venados, jabalíes, lobos, zorros y más de 130 especies de aves (alimoche, buho real, urogallo, mirlo acuático, etc.) (Simó et al., 1998: 147; Martínez Carrión, 2002: 24).

\subsection{Alto Campoo (Cantabria)}

La estación se ubica en el municipio cántabro de Reinosa, a una altitud de 1650 a 2175 metros, y a unos 90 km de Santander, 153 de Palencia, 190 de Bilbao y 330 de Madrid con acceso por Reinosa y Espinilla.

A fines del siglo XIX empieza a practicarse el esquí en la zona, imitando el modelo alpino, por santanderinos y campurrianos con algún turista inglés que acudían los domingos. En 1958 se empieza a utilizar el refugio del Club Alpino Tajahierro de Braña Vieja. En 1965 se pone en marcha el primer telesquí, el de El Tubo (García, 1985 : 251). Este mismo autor ofrece datos sobre el número de usuarios entre 1972 y 1983 que nos permiten conocer las grandes oscilaciones anuales: 20.000 en 1973, 77.000 en 1974, 138.000 en $1975,600.000$ en $1976,16.700$ en $1977,149.000$ en $1978,93.500$ en 1979, 186.000 en 1980, 214.300 en 1981, 378.000 en 1982 y 567.100 en 1983 (García, 1985 : 252). Estos altibajos se debieron a la mayor o menor abundancia de nieve, dificultades de acceso y a cambios económicos. 
En 1985, contaba con 4 telesillas y 6 telesquís, las pistas ocupaban unas 600 hectáreas y se podía practicar en ellas todas las modalidades de esquí (nórdico, alpino de competición...) gracias al balizamiento y a las máquinas pisapistas que garantizaban su perfecto estado. Un año después, José Ortega constata que «la pronunciada estacionalidad constituye uno de los rasgos más acusados del turismo en Cantabria» (Ortega, 1986: 446) y que se concentraba en verano con predominio de alojamiento extrahotelero en viviendas de familiares y residencias secundarias. Para Ortega Valcarcel, la puesta en marcha del complejo invernal de esquí por la Diputación Provincial pretendía promover el turismo alternativo al de playa y paliar los problemas de rentabilidad y estacionalidad aunque esta última perduraba (Ortega, 1986: 460-462). La Diputación puso en marcha el turismo y deporte de alta montaña para paliar la crisis de la comarca (Simó et al., 1998: 151).

Más optimista es la valoración de Arturo Queimadelos una década después: «desde el año de su fundación en 1966, el esfuerzo inversor, la mejora de sus dotaciones, la instalación de cañones de nieve artificial y la remodelación de las pistas han hecho de Alto Campoo el mejor enclave turístico de la comarca, tanto en invierno como en verano, dirigido al disfrute de un amplio abanico de posibilidades» (Queimadelos, 1997: 41). En esta positiva valoración influyen los $17 \mathrm{~km}$ esquiables, 9 remontes mecánicos (4 telesillas y 5 telesquís), los servicios de alquiler de equipamiento, guardería infantil y una variada gama de alojamientos (Queimadelos, 1997: 116), pero también juegan un papel decisivo el magnífico entorno con extensos bosques de hayas y robles, brezo, matorrales, pastos para ganadería extensiva, el ser lugar de paso de osos de Palencia a Cantabria, la abundancia de lobos, jabalíes, corzos y ciervos que se cazan en la Reserva Nacional de Saja, Valderredible y Valdeolea, la caza menor de sorda y perdiz, la pesca de truchas en los ríos Hijar, Ebro e Izarilla, la práctica de deportes acuáticos como rafting en los ríos y vela, surf, windsurf y remo en el pantano del Ebro y de otros deportes en toda la zona: senderismo, escalada, bicicleta de montaña, puenting, turismo ecuestre, etc. (Queimadelos, 1997: 116-117).

Un año después, Cristina Simó y Sara Vallhonrat califican Alto Campoo como un «complejo turístico moderno y funcional» (Simó et al., 1998: 150) que contaba con tres áreas de servicios (aparcamientos, restaurantes, cafeterías, apartamentos, albergues, guardería infantil) en Braña Vieja, Calgosa y Chivo, un moderno conjunto de remontes mecánicos y equipo de producción de nieve artificial, escuela de esquí con cuarenta profesores; alojamientos diversos en Villar, Abiada, Nestares, Reinosa, Olea y Arroyo; servicios médicos, farmacia, comercios, restaurantes y hoteles en Reinosa, etc. (Simó et al., 1998: 150-153).

En el 2000 contaba con unos $20 \mathrm{~km}$ esquiables repartidos entre 16 pistas: 4 verdes (muy fáciles), 5 azules (fáciles) y 7 rojas (difíciles) a las que se accedía por cinco telesillas y ocho telesquís con una capacidad aproximada de 12.000 personas/hora. La estación disponía de $3 \mathrm{~km}$ de nieve artificial con 80 cañones, dos escuelas de esquí, tres tiendas de alquiler de esquís, tres máquinas pisanieves, tres motonieves, servicio médico, servicio de evacuación, parque infantil, restaurantes, cafeterías, aparcamiento con 2.500 plazas a pié de pista, piscina, etc. Los alojamientos son abundantes: 300 plazas en la estación (150 en hoteles y 150 en albergues) y otras 1327 plazas en un radio de $35 \mathrm{~km}$. (350 en hoteles, 150 en hostales, 150 en casas rurales, 175 en apartamentos de alquiler, 100 en campings y 402 en albergues). En el entorno próximo a la estación se pueden practicar una gran variedad de actividades deportivas, recreativas y culturales como escalada, parapente, travesías de montaña, mountain-bike, excursiones a caballo guiadas, hidrospeed... A menos de $35 \mathrm{~km}$ de la estación existen gimnasio, campo de futbol, piscina climatizada, balneario de Corconte, nacimiento del Ebro, Reserva Nacional de Saja, ciudad romana de Julióbriga, iglesias románicas de Villacantid, Cervatos y San Martin de Elines, castillo de Argüeso, posibilidad de practicar rafting, vela ligera, winsurf, piragüismo y canoa, remo, etc. 
En la temporada 2000-2001, los pases de temporada para federados ascendían a más de 40.000 pesetas para adultos, más de 20.000 para infantiles y más de 25.000 para familiares (incluyendo IVA y seguro obligatorio) siendo gratuitos para menores de cinco años y consiguiendo precios especiales para grupos de 25 personas como mínimo. Los pases de un día ascendían a 3.200 pesetas por adulto y 2250 para infantiles y un paseo en telesilla costaba 1.000 pesetas. Los grupos escolares, de lunes a viernes, pagaban 2.500 pesetas por usar los remontes y dos horas de clases de esquí. En la «semana blanca», estos grupos escolares de más de veinticinco personas podían alojarse cinco días en el hotel de tres estrellas (La Corza Blanca) en la estación y recibir tres horas diarias de clase de esquí por 28.000 pesetas. La condición de complejo turístico se confirma con la posibilidad de compartir tarifas con el campo de golf de Nestares por adultos e infantiles, participación en trofeos, etc. (www.altocampoo.com). Estas variedades de ocio y la abundante nieve (entre 80 y $150 \mathrm{~cm}$ de espesor) permitieron un buen comienzo de temporada en diciembre de 2001 (El Diario Montañés, 2-12-2001: 64) repercutiendo de forma importante en la hostelería, servicios y comercio de Reinosa y del resto de la comarca campurriana (El Diario Montañés, 30-12-2001: 20).

Algunas de las instalaciones no han sido muy rentables. Es el caso de los 80 cañones de nieve artificial que se instalaron en 1989 y que, desde el principio, funcionaron regular por superarse los cero grados, ausencia de heladas y un elevado índice de humedad (un $85 \%$ frecuentemente por la proximidad de la costa y del pantano del Ebro), factores que dificultan la conservación de la nieve y la fabricación de nieve artificial para la que se requieren temperaturas de dos-tres grados bajo cero y humedad inferior al 40\%. Estas circunstancias se dan sólo de vez en cuando: en la temporada 2000-2001 no funcionaron ningún día y «nunca han funcionado a pleno rendimiento y han ido envejeciendo sin haberles sacado el rendimiento que se había previsto» (El Diario Montañés, 13-1-2002: 10).

Sigue habiendo grandes oscilaciones interanuales en el número de usuarios que, en la temporada 2000-2001, quedaron reducidos a unos 70.000 procedentes mayoritariamente de Cantabria, Vizcaya, Valladolid, Palencia, Burgos y Asturias, lo que se tradujo en un déficit de unos 50 millones de pesetas (El Diario Montañés, 30-11-2002: 45). En el 2002 se trata de paliar este escaso número de visitantes con un nuevo telesilla que subirá unas 1000 personas/hora, una nueva máquina pisapistas y mejoras en las carreteras de acceso a la estación, al campo de golf de Nestares y al pantano del Ebro, etc., dado que la nieve dificulta el tráfico al alcanzar frecuentemente los $15-30 \mathrm{~cm}$ de espesor en el casco urbano de Reinosa y más en el entorno de la estación (El Diario Montañés, 12-1-2003 :4). Al difícil tráfico con cadenas se unen las escasas pistas abiertas por el mal funcionamiento de los cañones de nieve artificial (El Diario Montañés, 9-2-2003: 10) aunque a finales del 2003 funcionaban 13 remontes y 21 pistas con $27^{\prime} 8 \mathrm{~km}$. esquiables (La Nueva España, 26-12-2003: 54).

En la temporada 2003-2004 hubo 90.063 usuarios y en la 2004-2005 se alcanzaron los 163.578, un $81 \%$ más con máximos en marzo (47.566), enero (39.901) y diciembre (36.050)(El Diario Montañés, 17-4-2005: 70). Entre el 5 y el 8 de diciembre de 2004 se superaron los 25.000 esquiadores y funcionaron todas las pistas y la superficie esquiable al haber entre 35 y $65 \mathrm{~cm}$ de espesor de nieve. El elevado número de visitantes a la estación y al Parque de Cabárceno obligó a cortar el tráfico (El Diario Montañés, 8-12-2004: 5; y 10-12-2004: 59). A comienzos del 2005 la nieve alcanza un espesor de 70-100 cm y abren 20 de las 22 pistas existentes. En Semana Santa, con espesores de 210-340 cm, se llega a unos 10.000 visitantes algunos días pese a los atascos en los accesos y a una ocupación casi completa (entre 70 y 100\%) de los hoteles de la zona (El Diario Montañés, 20-3-2005: 2). Para mejorar la oferta turística se prevé una mejora en los 17 km entre La Lomba y Braña 
Vieja, tres aparcamientos en esta localidad, crear una subestación eléctrica que suministre energía a los cañones y construir una piscina para embalsar el agua necesaria para fabricar nieve artificial (El Diario Montañés, 17-4-2005: 70).

En octubre de 2005 contaba con 23 pistas (4 verdes, 9 azules y 10 rojas) y un total de 27’775 km esquiables, con 5 telesillas y 8 telesquís con capacidad para 13.100 personas/ hora, posibilidad de paseo turístico en telesillas de Río Hijar y Pidruecos y una gama de servicios que se ha ampliado con un nuevo edificio a pié de pistas que incluye cafeterías, tiendas, zona infantil, taquillas, etc. Se incorpora una nueva pista azul (La Cabaña), se ensanchan las pistas azules y rojas, mejora y asfaltado de aparcamientos y de la carretera La Lomba-Calgosa, soterramiento de líneas eléctricas entre 1640 y $1850 \mathrm{~m}$ de altura, nueva máquina pisapistas con cabestrante y moto de nieve (www.altocampoo.com). En el puente de la Constitución de 2005 hubo unos 50.000 visitantes de los que la mitad eran esquiadores (El Diario Montañés, 11-12-2005: 55).

\section{Miniestación: El Morredero (León)}

Hace más de medio siglo que se empezó a practicar deporte de invierno en El Morredero, miniestación que cuenta con acceso desde Ponferrada por San Cristóbal de Valdueza, distando $23 \mathrm{~km}$ desde Ponferrada, 125 de León, 175 de Orense, 245 de La Coruña, 250 de Valladolid, 275 de Vigo y 400 de Madrid (www.elmorredero.com). La Diputación de León y el Ayuntamiento de Ponferrada mejoraron los accesos y potenciaron los deportes de nieve en la zona (Diario de León, 4-10-2003: 4). En diciembre de 2005 cuenta con 7 pistas balizadas ( 2 verdes, 2 azules, 2 rojas y 1 negra) que sólo suman 3’22 km esquiables y a las que se accede con tres remontes ( 2 telesquís y 1 telebaby) que tienen capacidad para subir 2.270 personas/hora, abriendo fines de semana y festivos cuando se superan los $15 \mathrm{~cm}$. de espesor (Diario de León, 17-12-2005: 20).

La Asociación de Amigos de El Morredero, ha realizado mejoras con la ayuda del Ayuntamiento de Ponferrada que financió la construcción de un edificio para servicios varios y un telesquí (Mirador de El Bierzo) y la Diputación de León subvencionó la colocación de $3 \mathrm{~km}$ de paravientos para la temporada 2005-2006 (www.elmorredero.com), invirtiendo esta última 138.584'76 euros en esta mejora que permite conservar la nieve en la parte alta de las pistas (www.nevasport.com). La miniestación cuenta con escuela de esquí y snowboard en la que cuatro profesores imparten clases a todos los niveles con precios que oscilan en función del número de alumnos. En el entorno próximo hay abundantes alojamientos: 8 hoteles, 6 hostales residencia, 1 albergue de peregrinos, 2 casas rurales y 7 pensiones en Ponferrada, 1 casa rural en Campudo, 9 en Espinoso de Campudo, 2 en Peñalba de Santiago y 1 en Toral del Merayo (www.ponferrada.org).

\section{Estaciones de esquí en construcción}

La creciente demanda propicia las ampliaciones y mejoras apuntadas en las estaciones y la construcción de otras nuevas como Fuentes de Invierno y San Glorio.

\subsection{Fuentes de Invierno (Asturias)}

En junio de 2001 se hace público el proyecto de la estación de esquí Fuentes de Invierno en la vertiente asturiana del puerto de San Isidro, municipio de Aller, con $20 \mathrm{~km}$ de pistas esquiables con cotas entre 1700 y 2000 metros y una capacidad de unos 14.000 esquiadores/hora (La Voz de Asturias, 20-6-2001: 29). A finales de 2002 se hacen propuestas 
sobre la futura estación y sus complementos y se analiza una posible fusión con la estación leonesa de San Isidro para realizar una gestión compartida y mejora conjunta de accesos propiciada por ambas comunidades autónomas, lo que las convertiría en la más grande de la Cordillera Cantábrica y atraería aficionados asturianos, leoneses, gallegos y portugueses (La Voz de Asturias, 22-9-2002: 13).

Parte de las inversiones proceden de los fondos para las comarcas mineras y surgen numerosas ofertas de equipamientos, especialmente para la construcción de pisos y chalets en el entorno. La previsión de unas 1.500 viviendas obliga a modificar el PGOU de Aller (La Nueva España, 8-11-2002: 14), realizar un plan especial medioambiental, etc. Las obras de viviendas comienzan en 2003 tras subasta pública entre empresas, construyéndose también un parking para 2.500 vehículos, principalmente autobuses. Parte de los servicios hoteleros tienen subvenciones del PRODER (La Voz de Asturias, 14-11-2002: 24).

En la primera fase, con un presupuesto de 10'8 millones de euros, se incluyen la carretera de acceso desde la del puerto de San Isidro-Cabañaquinta, parte del aparcamiento, servicios de luz, agua y teléfono, el edificio principal con cafetería, restaurante, área administrativa, tres telesillas y un telesquí, 14 pistas ( 2 verdes, 5 azules, 5 rojas y 2 negras) con 8' $5 \mathrm{~km}$ esquiables que podrán acoger a unos 3.500 esquiadores/hora desde la temporada 2005-2006. En una segunda fase está previsto invertir 5'8 millones de euros en mejorar accesos, sistemas de nieve artificial, etc. El presupuesto global, incluyendo la zona residencial con chalets, viviendas adosadas, bloques de apartamentos, etc., asciende a unos 42 millones de euros, convirtiéndose en uno de los proyectos más importantes de la zona (La Voz de Asturias, 16-9-2003: 23) y en una de las mayores y mejores estaciones de la Cordillera Cantábrica, con más de $23 \mathrm{~km}$ repartidos entre 18 pistas para todos los niveles de esquiadores y posibilidad de ofertar actividades complementarias como senderismo, rutas de mountain bike, paseos a caballo, ascenso en telesillas en verano, etc.

Antes de la puesta en marcha de la estación, Aller acapara ya una gran cantidad de las inversiones del PRODER de la comarca Montaña Central para inversiones turísticas en previsión de un elevado número de visitantes en un futuro próximo. Apoyados por estas subvenciones europeas, el concejo de Aller contará con seis hoteles de nueva construcción: dos en Collanzo y uno en Cuérigo, Cuevas, Santibáñez de Murias y Felechosa. En esta última localidad se reformará otro hotel para obtener una categoría más alta. Los planes contemplan también tres casas de aldea en Serrapio, Nembra y Pelúgano y un núcleo de apartamentos rurales en Bello. El Ayuntamiento ya ha proyectado 1.500 viviendas de nueva construcción entre Pino y Felechosa (La Voz de Asturias, 16-1-2004: 40). Estas profundas transformaciones han propiciado numerosas críticas y alegaciones de grupos ecologistas por afectar a especies protegidas como el oso pardo, urogallo, alimoche y águila real, mientras los partidarios piden que el tren de FEVE llegue a Felechosa para facilitar el acceso a turistas (La Voz de Asturias, 14-2-2004: 33). Se prevé dejar unos 20.000 metos cuadrados a pié de la futura estación para construir más hoteles, hostales y comercios (La Voz de Asturias, 30-4-2004: 29).

La Comisión de Asuntos Medioambientales de Asturias (CAMA) ha dado el visto bueno al proyecto Fuentes de Invierno con algunas modificaciones como repoblar forestalmente 150 ha, depuración adecuada de aguas residuales, atenuación de ruidos y elaboración de un programa de vigilancia ambiental (La Voz de Asturias, 12-5-2004: 32). Se incluyen otras medidas encaminadas a reducir el impacto de los aparcamientos, retirar los cañones de esquí fuera de la temporada invernal, la estación sólo se utilizará hasta mayo, se prohibe circular a todoterrenos y motos de trial, los ruídos deberán ser inferiores a 55 decibelios, el edificio de nieve artificial estará insonorizado, se prohibe el uso de herbicidas y pesticidas, la estación y su entorno no podrá ser usado en verano para turismo salvo senderismo 
y montañismo como ocurre en Pajares. Estas normas se incluyen en la Declaración de Impacto Ambiental publicada el 23 de junio de 2004 en el Boletín Oficial del Principado de Asturias (BOPA) tras ser aprobada por el Gobierno regional.

La falta de acuerdo entre Asturias y León sobre la posible unión o gestión compartida con San Isidro retrasó las obras. Mientras Asturias se inclina por gestión compartida, León propone unir ambas estaciones por un remonte y una carretera (La Nueva España, 19-92004: 17), coincidiendo unicamente en la promoción turística conjunta. En septiembre de 2004 comienzan las obras de construcción del edificio de servicios, aparcamientos y accesos (El Comercio, 17-9-2004: 24) pero en mayo de 2005 aún no se había adjudicado la de las pistas de esquí a la que optaban cinco empresas (La Voz de Asturias, 27-5-2005: 26) por lo que, unido a trámites administrativos y ambientales, se retrasa su apertura hasta fines de 2006. El Gobierno del Principado estudia actividades complementarias para cuando no se pueda esquiar como aulas de la naturaleza destinadas a escolares y otras similares a las practicadas en Valgrande-Pajares. El Ayuntamiento de Aller prepara cursos formativos para que los vecinos del concejo puedan optar a los aproximadamente sesenta puestos de trabajo de la futura estación de esquí. La Consejería de Cultura y Turismo del Principado invertirá en ella 6'89 millones de euros en el 2006 (La Voz de Asturias, 16-11-2005: 63).

\subsection{San Glorio (León)}

A comienzos de 2002, las juntas vecinales de Portilla y Llánaves de la Reina, en el municipio de Boca de Huérgano, proponen crear una estación de esquí sobre 500-600 hectáreas y que la Junta de Castilla-León recalifique el suelo de rural a estación de esquí (Diario de León, 16-3-2002: 24). La propuesta es apoyada por los municipios de la Mancomunidad de la Montaña de Riaño y sería la séptima de la cordillera. El principal problema es medioambiental ya que la zona de Llánaves, donde se ubicarían las pistas y remontes, está incluída en el parque de Picos de Europa (La Nueva España, 27-2-2002: 15) ${ }^{8}$. Distintos partidos políticos insisten a la Junta de Castilla-León para que elabore la Evaluación de Impacto Ambiental y se recalifiquen los terrenos y se negocie con Asturias y Cantabria al considerarse importante para el desarrollo de las zonas leonesas y cántabras próximas. De las 1300 hectáreas reutilizables, 120 estarían en Cantabria y 1180 en Boca de Huérgano (León) (Diario de León, 2-3-2003: 22).

Isidoro Rodríguez y Adelino Campos señalan que «sin duda alguna la vertiente leonesa de la zona de Peña Prieta es el lugar que presenta las mejores condiciones para la práctica del esquí de montaña en toda la Cordillera Cantábrica, y por ello es frecuente encontrarse con esquiadores-alpinistas la mayor parte de los fines de semana de la temporada, que en este lugar suele ser muy amplia, pues abarca todo el invierno y una buena parte de la primavera» (Rodríguez Cubillas et al., 2003: 46). La reconversión de este paraje en la moderna estación de San Glorio la consideran buena para la economía de la zona pero «mala noticia esta, por otra parte, para los montañeros que no necesitamos de los remontes mecánicos para alcanzar las alturas de estas montañas, ni somos amigos del bullicio ni del fuerte impacto, tanto físico como ecológico, que las instalaciones de esta gran estación causarían» (Rodríguez Cubillas et al., 2003: 46). Estos autores proponen la realización de rutas en nieve para esquiadores-montañeros, potenciadas desde los años setenta y que, a comienzos del siglo XXI, tienen un carácter competitivo (lo que prima es hacerlas en el

8 En Llánaves se instaló ya en la temporada 1975-1976, a título experimental, un telesquí portátil, con un éxito de público que incitó a crear una pequeña estación de invierno (Escuela, 1978, t. 1: 61). 
menor tiempo posible) y que pueden competir y/o complementar a las estaciones de esquí al representar una actividad intermedia entre el alpinismo y el esquí.

La Diputación de León incluye en sus presupuestos de 2004 unos 480.000 euros destinados a estudios medioambientales sobre la estación de San Glorio y pide a la Junta de Castilla-León que invierta 12 millones a poner en marcha los accesos a la futura estación. La de San Isidro ofrece dar cursos gratuitos para la formación de monitores y preparadores de esquí de la futura estación de San Glorio (Diario de León, 11-11-3003: 10).

En abril de 2004, los municipios de Boca de Huérgano, Riaño, Burón (León), Vega de Liébana (Cantabria) y Crémenes, Guardo y Cistierna (Palencia) piden que se apruebe ya la estación «Tres Provincias» en San Glorio ya que permitiría recuperar la población de la zona, que se ha reducido un $40 \%$ en veinte años, y su economía, afectada por el pantano de Riaño y el cierre de minas (El Diario Montañés, 25-4-2004: 20). A finales de 2004, la Diputación de León dispone de 1.200 hectáreas (hasta entonces de pastos) cedidas por las juntas vecinales de Llánaves de la Reina y Portilla para la primera fase de San Glorio. Según el proyecto inicial, la estación contará con $40 \mathrm{~km}$ esquiables a una altitud media de $2.300 \mathrm{~m}$, dentro de un espacio de gran valor medioambiental, incluído en la red Natura 2000, lo que ha provocado la oposición de ecologistas por lo que se prevé que las obras se inicien a principios de 2006 (La Nueva España, 8-11-2004: 12).

A comienzos de 2005 se presenta un proyecto de un grupo de productores privados para que San Glorio tenga $80 \mathrm{~km}$ de pistas (el doble de lo previsto inicialmente) con un coste de 100 millones de euros, 30 más de los presupuestados anteriormente (La Nueva España, 30-1-2005: 14). La Junta Rectora del Parque Natural de Fuentes Carrionas-Montaña Palentina aprobó autorizar la macroestación de esquí de San Glorio en el límite de Cantabria, León y Palencia, que tiene también el visto bueno de la Junta de CastillaLeón y de 14 ayuntamientos afectados que apoyan el proyecto de la empresa privada Tres Provincias. Será el mayor de la Cordillera Cantábrica con 80 km esquiables, más que Valgrande-Pajares, San Isidro, Alto Campoo y Fuentes de Invierno juntas, igualando a Baqueira Beret y Sierra Nevada. La inversión ascenderá a 100 millones de euros y generará 400 empleos al contar con actividades de ocio todo el año, con una cabida de entre 12.350 visitantes/día si se opta por la calidad y 22.000 si se acepta la saturación (La Nueva España, 27-3-2005: 14). El proyecto se considera respetuoso con el entorno ambiental y el desarrollo urbanístico complementario se realizará en el entorno de los pueblos (Diario de León, 15-5-2005: 26), lo que no impide las críticas de ecologistas e Izquierda Unida de Castilla-León y Cantabria a través de la plataforma «No a San Glorio» (El Diario Montañés, 6-11-2005: 19).

\subsection{Otros proyectos de estaciones de esquí}

Otros municipios de la Cordillera Cantábrica han realizado planes para la posible creación de otras estaciones de esquí (Quirós) o de pistas de esquí de fondo (Somiedo).

El Ayuntamiento de Quirós (Asturias) empezó en 1998 a debatir la creación de una estación en Socellares (la más pequeña) o en Agüeria (con 22 km de pistas), inclinándose por la primera opción en junio de 2002 ante la aprobación de Fuentes de Invierno (La Nueva España, 7-7-2002: 12). La estación contaría con 16 km en la vega de Socellares en el macizo de Ubiña y los servicios se ubicarían en los pueblos de Ricabo y Bueida. La Comisión de Urbanismo y Ordenación del Territorio de Asturias (CUOTA) rechazó el proyecto por ser una zona de «interés comunitario» (LIC) y de especial protección para aves (ZEPA) y osos (La Nueva España, 14-9-2002: 20) lo que influyó para eliminarla de la lista de posibles ayudas de los fondos mineros (La Voz de Asturias, 20-1-2003: 19). 
El Ayuntamiento asturiano de Somiedo prepara un proyecto destinado a potenciar la práctica del esquí de fondo en el parque natural a través de cuatro rutas por la demanda de deportistas que lo practican en las inmediaciones del puerto. Se señalizan las pistas al no verse afectadas por la normativa de parques naturales que prohibe la construcción de estaciones de esquí. Las rutas elegidas son las del Puerto, la del Camin de La Mesa (que comunica San Lorenzo con Saliencia), la del Valle del Lago (concluye en el lago del Valle) y la de Cueiru a la Bustariega. Todas están a más de $1600 \mathrm{~m}$. de altura y tienen nieve frecuentemente en los primeros meses del año y son recorridos con poca pendiente por lo que pueden atraer a visitantes que practiquen este deporte y disfruten con elementos etnográficos como los teitos, la gastronomía de la zona ${ }^{9}$, la policromía de los bosques somedanos, las berreas, etc., contribuyendo a desestacionalizar el turismo del municipio.

\section{Bibliografía $^{10}$}

ANTÓN CLAVE, S. (2000): «Actividades y espacios turísticos: hacia la sociedad postindustrial» en LÓPEZ PALOMEQUE, F. (Coord): Geografía de Europa, Barcelona, Ariel, 620 pp., cfr. pp. 357-377.

BARRADO TIMÓN, D.A. (1999): Actividades de ocio y recreativas en el medio natural de la Comunidad de Madrid, Madrid, Consejería de Medio Ambiente, 348 pp.

CALLIZO, J. y LACOSTA, A.J. (1999): «La actividad turística en Aragón» en AECIT: La actividad turística española en 1997, Madrid, 622 pp., cfr. pp. 225-248.

CÁNCER POMAR, L. y PÉREZ CABELLO, F. (2001): «El impacto ambiental de las pistas de esquí en los dominios supraforestales: cambios en los paisajes rurales altimontanos», Ería, 56, pp. 299-307.

CARBAJOSA, C. (1999) Participación deportiva de las mujeres asturianas (1939-1977), Oviedo, Universidad, $408 \mathrm{pp}$.

CASTELLS, M. (Dir)(1994): Estrategias para la reindustrialización de Asturias, Madrid, Civitas, $762 \mathrm{pp}$.

ESCUELA TÉCNICA SUPERIOR DE INGENIEROS DE MONTES (1978): Ordenación del paisaje, Madrid, 2 tomos, $756 \mathrm{pp}$.

FEO PARRONDO, F. (2005): «Turismo gastronómico en Asturias», Cuadernos de Turismo, 15, pp. 77-96.

GARCÍA DE ENTERRÍA, J. (1985): «Estación invernal de Alto Campoo» en Gran Enciclopedia de Cantabria, Santander, t. 3, pp. 251-252.

GONZÁLEZ CRESPO, J.L. y HACAR RODRÍGUEZ, F. (2003): Pajares, no hay palabras para describirlo, Oviedo, ICMA, $190 \mathrm{pp}$.

GONZÁLEZ FERNÁNDEZ, M.T. y MOSCOSO SÁNCHEZ, D.J. (2004): «La montaña como observatorio de lo social» en Turismo, ocio y deporte, La Coruña, Universidade, 534 pp., cfr. pp. 441-463.

HERZOG, M. et al. (1967): La montaña, Barcelona, Labor, 752 pp.

LÓPEZ PALOMEQUE, F. (1996): «Turismo de invierno y estaciones de esquí en el Pirineo catalán», Investigaciones Geográficas, 15, pp. 19-39.

LÓPEZ PALOMEQUE, F. (1999): «El turismo de montaña y nieve en España: análisis estructural y balance de coyuntura» en AECIT: La actividad turística española en 1997, Madrid, 622 pp. cfr. pp. 479-490.

LUEJE, J.R. (1984): La cordillera cantábrica, Oviedo, Caja de Ahorros de Asturias, 216 pp.

9 El turismo gastronómico tiene gran importancia en el Principado, organizando ferias, fiestas, certámenes y jornadas gastronómicas el 82\% de los municipios asturianos (Feo, 2005: 77-96).

10 Además de la bibliografía citada se han utilizado numerosas noticias de periódicos de ámbito nacional (El País y El Mundo) y de la zona (La Voz de Galicia, La Nueva España, La Voz de Asturias, El Comercio, Diario de León y El Diario Montañés) y de la revista La Maniega (Cangas del Narcea). 
MARTÍNEZ CARRIÓN, F. (2002): Guía turística de Puebla de Lillo, León, Ayuntamiento de Puebla de Lillo, 98 pp.

MARTÍNEZ FERNÁNDEZ, L.C. (2003): «De El Brañillín a la estación de esquí de Valgrande-Pajares: cambios en la propiedad, el aprovechamiento y la organización espacial de una antigua braña vaqueira en las montañas de Lena (Asturias)», Ería, 61, pp. 215-226.

MARTÍNEZ DE PISÓN, E. (2002): El Alto Pirineo, Zaragoza, Biblioteca Aragonesa de Cultura, $190 \mathrm{pp}$.

MARTÍNEZ SALINAS, V. (1998): «Turismo de nieve: Sierra Nevada», Cuadernos de Turismo, 2, pp. 115-125.

MENÉNDEZ PIDAL, J. (1898): «Lena» en BELLMUNT, O. Y CANELLA, F.: Asturias, Gijón, t. 2, pp. 283-331.

ORTEGA VALCÁRCEL, J. (1986): Cantabria 1886-1986. Formación y desarrollo de una economía moderna, Santander, Cámara de Comercio, Industria y Navegación, 502 pp.

QUEIMADELOS, A. (1997): Reinosa y Campoo. Guía turística, Santander, Génesis, 144 pp.

RODRÍGUEZ, F. y MENÉNDEZ, R. (2005): Geografía de Asturias, Barcelona, Ariel, 406 pp.

RODRÍGUEZ CUBILLAS, I. y CAMPOS NIÑO, A. (2003): Esquí de montaña en la Cordillera Cantábrica y Picos de Europa. 35 itinerarios a través de los macizos cantábricos, Madrid, Desnivel, $182 \mathrm{pp}$.

RODRÍGUEZ LAGO, J. (1995): «Reflexiones económicas sobre el turismo de montaña en la provincia de León» en Posibilidades del turismo de montaña en la provincia de León, León, Universidad, 188 pp., cfr. pp. 19-40.

SENDÍN GARCÍA, M.A. (1997): «La montaña central asturiana» en ALVARGONZÁLEZ, R. (Coord): Asturias. Montes y valles, Madrid, Mediterráneo, 252 pp. cfr. pp. 165-182.

SIMO, C. y VALLHONRAT, S.(1998): Aeroguía del esquí. España y Andorra, Barcelona, Planeta, $192 \mathrm{pp}$.

TORRES LUNA, M.P. et al. (1998): «Turismo y ocio» en Enciclopedia temática de Galicia. Geografía, Madrid, Interliber, 240 pp., cfr. pp. 169-177.

VALENZUELA RUBIO, M. (1998-99): «La imagen geográfica del turismo en España (1962-1998). Crónica breve de una gran expansión», Boletín de la Real Sociedad Geográfica, 134-135, pp. 67-103.

VEGA PATO, T. (1991): Tierras de Trives y Manzaneda, León, Everest, 128 pp.

VERA, J.F. (Coord.) (1997): Análisis territorial del turismo, Barcelona, Ariel, 444 pp.

Webs: www.altocampoo.com; www.dipuleon.com/sanisidro; www.elmorredero.com; www.estacionsanisidro.com; www.leitariegos.com; www.manzaneda.com; www.nevasport.com;

www.ponferrada.org ; www.princast.es/deporteasturiano; www.princast.es/valgrandepajares;

www.san-isidro.net; www.valgrande-pajares.com; www.valgrande-pajares.net 